\title{
Clinical and radiological outcomes of arthroscopically assisted cannulated screw fixation for tibial eminence fracture in children and adolescents
}

\author{
Chang Ho Shin, Doo Jae Lee, In Ho Choi, Tae-Joon Cho and Won Joon Yoo*
}

\begin{abstract}
Background: The purpose of this study was to determine the efficacy and complications of arthroscopically assisted reduction and fixation with cannulated screws for tibial eminence fracture in skeletally immature patients.

Methods: This was a retrospective case series study. Forty-eight patients who were skeletally immature at the time of tibial eminence fracture were treated in a tertiary children's hospital between May 2004 and August 2015. Twenty-one patients were excluded due to non-operative treatment $(n=10)$, other surgical treatments $(n=9)$, multiple fracture $(n=1)$, and follow-up $<1$ year $(n=1)$. Twenty-seven knees of 27 patients were analyzed. Avulsed fragment was reduced arthroscopically. One to three cannulated screws $(4.0 \mathrm{~mm}$ or $5.0 \mathrm{~mm}$ in diameter) were used for fixation. Passive knee motion was started in 3-4 weeks. Clinical outcomes were evaluated by Lysholm score, instability of the knee, and complications. Radiological outcomes including nonunion and malunion of the avulsed fragment and physeal growth disturbance were evaluated.

Results: Mean age at the time of surgery was 10.1 years (range, 6.2 to 13.8 years). Patients were followed up for a mean of 3.9 years (range, 1.0 to 7.6 years). Fracture types included type III $(n=13)$, type II $(n=12)$, and type IV $(n=2)$ according to Zaricznyj modification of Meyers and McKeever classification. Meniscus was entrapped in five patients. Six patients showed concomitant meniscal tear. Mean Lysholm score at the latest follow-up was 95 (range, 78 to 100). Joint instability was not observed in any patient except one (instability of $5-10 \mathrm{~mm}$ ). All patients showed full range of knee motion except one (10 degrees of flexion contracture). Screw head impingement against intercondylar notch of the femur was observed in two patients during screw removal procedure. Five knees showed prominent tibial eminence without symptoms. The injured lower limb was longer than the contralateral normal side by a mean of 6 . $2 \mathrm{~mm}$ (range, -4 to $18 \mathrm{~mm}$ ).
\end{abstract}

Conclusions: Arthroscopically assisted reduction and fixation with cannulated screws is an effective and safe surgical option for treating tibial eminence fracture with few complications.

Keywords: Tibial eminence fracture, Cannulated screw, Arthroscopically assisted reduction, Skeletally immature patient

* Correspondence: yoowj@snu.ac.kr

Department of Orthopaedic Surgery, Seoul National University College of

Medicine, 101 Daehak-ro Jongno-gu, Seoul, 03080, Republic of Korea 


\section{Background}

Tibial eminence fracture is a relatively rare injury, with an incidence of approximately 3 per 100,000 per year, which mainly occurs in children and adolescents [1]. It is thought to be a pediatric equivalent of anterior cruciate ligament (ACL) tears in adults [1-3]. Meyers and Mckeever classified this fracture into three types initially in 1959 while Zaricznyj added type IV fracture in 1977 [2, 4]. Non-displaced type I fracture and slightly displaced type II fracture can be managed conservatively with successful closed reduction, while displaced fracture requires surgical treatment $[5,6]$.

Various surgical fixation methods are available. Cortical screw, headless screw, suture using absorbable or nonabsorbable material, suture anchor, or Kirschner wire can be used to fix the fracture [7-12]. As joint stiffness associated with delayed knee mobilization after surgery is the main complication in treatment of tibial eminence fracture [13-16], the ideal fixation device should provide sufficient initial fixation strength to allow a more aggressive rehabilitation protocol. In addition, the fixation device should not traverse the proximal tibial growth plate in skeletally immature patients because of the possibility of partial physeal arrest $[17,18]$. Some biomechanical studies have investigated fixation power of several internal fixation devices with different results [19-24]. Some clinical studies have reported outcomes of various fixation devices and surgical techniques with pros and cons [9, 10, 25-29]. Cannulated screw fixation has been used widely in the treatment of the tibial eminence fracture [27, 30-34]. However, only a few articles have studied this subject in skeletally immature patients who are different from adult patients in terms of knee size, screw length, and number of screws implanted [27, 33, 34].

The purpose of this study was to determine the efficacy and complications of arthroscopically assisted reduction and fixation with cannulated screws for tibial eminence fracture in skeletally immature patients.

\section{Methods}

This retrospective study was approved by our Institutional Review Board (H-1611-007-803). A total of 48 patients who sustained tibial eminence fracture before skeletal maturity and were treated in a tertiary children's hospital between May 2004 and August 2015 were reviewed. Twenty-one patients were excluded because of non-operative treatment $(n=10)$, other surgical treatments $(n=9$, arthroscopic suture fixation in six patients, open reduction and fixation with cannulated screws in one patient, arthroscopic partial excision of tibial eminence and femoral intercondylar notchplasty in one patient, and arthroscopic exploration in one patient), multiple fractures in other body parts $(n=1)$, and follow-up of less than 1 year $(n=1)$. After excluding these patients, 27 knees of 27 patients remained eligible for inclusion.

\section{Surgical technique}

All operations were performed by a single surgeon (W.J.Y.). In a fresh case of fracture, the hematoma was removed first and the avulsed fragment was pushed using a guide pin to achieve reduction while extracting the interposed meniscus or intermeniscal ligament using an arthroscopic probe. And then other guide pins were inserted before inserting a screw to prevent posterior displacement or rotation of the avulsed fragment. Guide pins were driven at a 30-50 degree sagittal plane angle to the growth plate of the proximal tibia. One to three ASNIS III cannulated screws (4.0 or $5.0 \mathrm{~mm}$ diameter; Stryker Corporation, Kalamazoo, MI, USA) were used with or without washers. Diameter and length of screws, number of screws implanted, and usage of washers were determined intraoperatively considering fracture pattern and the size of the avulsed osteochondral fragment and the knee. Intraoperative fluoroscopy was used to avoid iatrogenic physeal penetration by screws. In a delayed case of fracture, an arthroscopic burr and curette were used to remove the organized hematoma and fibrocartilaginous tissues on the old fracture surfaces before reduction and fixation of the avulsed fragment. In some delayed cases in which reduction was difficult to achieve, a temporary suture that had been passed through ACL was pulled out under meniscus to reduce the fragment, and a guide pin was inserted.

\section{Post-operative management/rehabilitation protocol}

Postoperatively, a long leg splint was applied for 3-4 weeks with the knee in 30 degrees of flexion. Passive knee motion was then started. Weight bearing was permitted at 6 weeks after the surgery. Patients were allowed to return to sports at 3 to 4 months after the surgery.

\section{Clinical evaluations}

Clinical outcomes were evaluated with regard to the presence or absence of arthrofibrosis, instability of the knee, Lysholm knee score [35], and complications including screw head impingement at the latest follow-up. Arthrofibrosis was defined as lack of 10 degrees or more of extension, or 15 degrees or more of flexion compared to the uninjured side at 3 months after treatment [13, 14]. Instability was evaluated using the side-to-side difference of Lachman and anterior drawer tests, and anterior tibial translation at 30 degrees of flexion in a KT-1000 arthrometer (MEDmetric, San Diego, CA, USA). Instability tests were performed by a single investigator (W.J.Y.). Lysholm knee score was obtained for $22(81 \%)$ patients. KT-1000 measurements were obtained for 17 (63\%) patients.

\section{Radiological evaluations}

Radiological outcomes were evaluated with regard to penetration of proximal tibial growth plate by screws, nonunion and malunion of the avulsed fragment, and physeal growth 
disturbances such as leg length discrepancy (LLD) and angular deformity. LLD was assessed in 20 (74\%) patients using standing whole leg anteroposterior (AP) radiograph at the latest follow-up. A patient who had suffered a femoral shaft fracture in the ipsilateral leg 5 years before tibial eminence fracture was excluded from the evaluation of LLD. Femoral length was determined by measuring the distance from the highest point of femoral head to the lowest point of medial femoral condyle. Tibial length was determined by measuring the distance from the medial tibial plateau to the tibial plafond on whole leg AP radiograph. Magnetic resonance imaging (MRI) study was taken preoperatively for all patients except two who were under Medical Aid Program. Based on MRI and arthroscopic findings, associated injury of the knee was evaluated.

\section{Statistical analysis}

Mann-Whitney $\mathrm{U}$ test was used to compare means between two groups. To assess the relationship between the degree of laxity measured by KT-1000 or Lachman test and the Lysholm score, Spearman's rank correlation test was used. $P$ values of less than 0.05 were considered statistically significant.

\section{Results}

Descriptive data of the 27 patients are summarized in Table 1 . There were 19 boys and 8 girls. Their age at the time of surgery (mean \pm standard deviation) was $10.1 \pm$ 2.2 years (range, 6.2 to 13.8 years). Follow-up period was $3.9 \pm 2.2$ years (range, 1.0 to 7.6 years). The interval from trauma to surgery was $48.9 \pm 143.0$ days (range, 0 to 731 days). The interval was more than 30 days in $6(22 \%)$ patients. Fractures were caused by fall $(n=11,41 \%)$, sports injuries $(n=10,37 \%$, skiing in 8 patients, sprinting in 1 patient, and soccer in 1 patient), traffic accident $(n=2,7 \%)$, or collision with another person $(\mathrm{n}=2,7 \%)$. Fracture type was type III in 13 (48\%) patients, type II in 12 (44\%) patients, and type IV in 2 (7\%) patients according to Zaricznyj modification of Meyers and McKeever classification [4, 36].

The number of screws used for fixation was one in three (11\%) patients, two in $19(70 \%)$ patients, and three in 5 (19\%) patients. Washer was used in conjunction with the screw in 11 (41\%) patients who had cartilaginous avulsion fragment with or without very thin bone sliver. The mean sagittal angle of the screw to the growth plate of the proximal tibia was $37.6^{\circ} \pm 8.0^{\circ}$ (range, $20^{\circ}$ to $53.4^{\circ}$ ). Five (19\%) patients showed entrapment of the meniscus or intermeniscal ligament under a displaced tibial eminence fragment (intermeniscal ligament in 2 patients, medial meniscus in 2 patients, and lateral meniscus in 1 patient) (Fig. 1). Screw removal was routinely performed for all patients at postoperative $8.6 \pm 5.9$ months (range, 3.0 to 33.7 months).

\section{Clinical outcomes}

Screw head impingement against femoral notch was observed in two (7\%) patients during screw removal. Of these two patients, one patient was treated with one $4.0 \mathrm{~mm}$ screw and one $5.0 \mathrm{~mm}$ screw for neglected type IV fracture at 141 days after trauma. Hypertrophy of distal femoral articular cartilage was observed during screw removal procedure. This was probably due to irritation by screws. Range of knee motion was $15^{\circ}$ to $120^{\circ}$ before removal of screws and $-5^{\circ}$ to $145^{\circ}$ at the latest follow-up. The other patient was treated with one $4.0 \mathrm{~mm}$ screw and one $5.0 \mathrm{~mm}$ screw for type III fracture at 32 days post trauma (Fig. 2). Incomplete distal femoral metaphyseal fracture occurred due to vigorous physical therapy by mother at postoperative 2.5 months. This interrupted physical therapy for 3 weeks. Range of knee motion was $20^{\circ}$ to $115^{\circ}$ at postoperative 6 months when screws were removed. The head of $5.0 \mathrm{~mm}$ screw impinged against the lateral portion of medial femoral condyle and caused extension deficit of the knee. Range of motion of $10^{\circ}$ to $120^{\circ}$ could be easily obtained after screw removal. On post-removal radiograph, radiolucent gap between avulsed fragment and host bone was observed. This was thought to be a fibrocartilaginous union to lead to bony union which was expected. However, this patient was lost to follow-up at 3 months after screw removal. When he returned to the clinic at post-removal 18 months, he showed a $25^{\circ}$ of flexion contracture. Plain radiographs revealed re-displaced avulsion fragment. Open reduction and internal fixation with two $5.0 \mathrm{~mm}$ cannulated screws with two washers were performed. At the latest follow-up, he showed a $10^{\circ}$ of flexion contracture with further flexion of $130^{\circ}$. Bony union of avulsed fragment was achieved. There were no signs of knee instability. This patient was the only one who showed arthrofibrosis. All other 26 patients had full range of knee motion at the latest follow-up.

Side-to-side difference in Lachman test was less than $3 \mathrm{~mm}$ in 23 (85\%) patients, 3 to $5 \mathrm{~mm}$ in 2 (7\%) patients, and 5 to $10 \mathrm{~mm}$ in 1 (4\%) patient. Side-to-side difference in anterior drawer test was less than $3 \mathrm{~mm}$ in $24(89 \%)$ patients, 3 to $5 \mathrm{~mm}$ in 2 (7\%) patients, and 5 to $10 \mathrm{~mm}$ in 1 (4\%) patient. Of 17 patients who were examined with KT1000 arthrometer, manual maximum side-to-side difference was less than $3 \mathrm{~mm}$ in 14 (82\%) patients, 3 to $5 \mathrm{~mm}$ in 2 (12\%) patients, and $5 \mathrm{~mm}$ in $1(6 \%)$ patient. The patient who had 5 to $10 \mathrm{~mm}$ of side-to-side difference in physical examinations was the patient who showed $5 \mathrm{~mm}$ of sideto-side difference in the KT-1000 arthrometer measurement. He had been treated with one $4.0 \mathrm{~mm}$ screw and two $5.0 \mathrm{~mm}$ screws in conjunction with three washers for type II fracture at 36 days after trauma. Continuity of his ACL was maintained on preoperative MRI and arthroscopy. At the day of screw removal, however, the diameter of ACL decreased up to $50 \%$ of normal diameter, although the 
Shin et al. BMC Musculoskeletal Disorders (2018) 19:41

Page 4 of 9

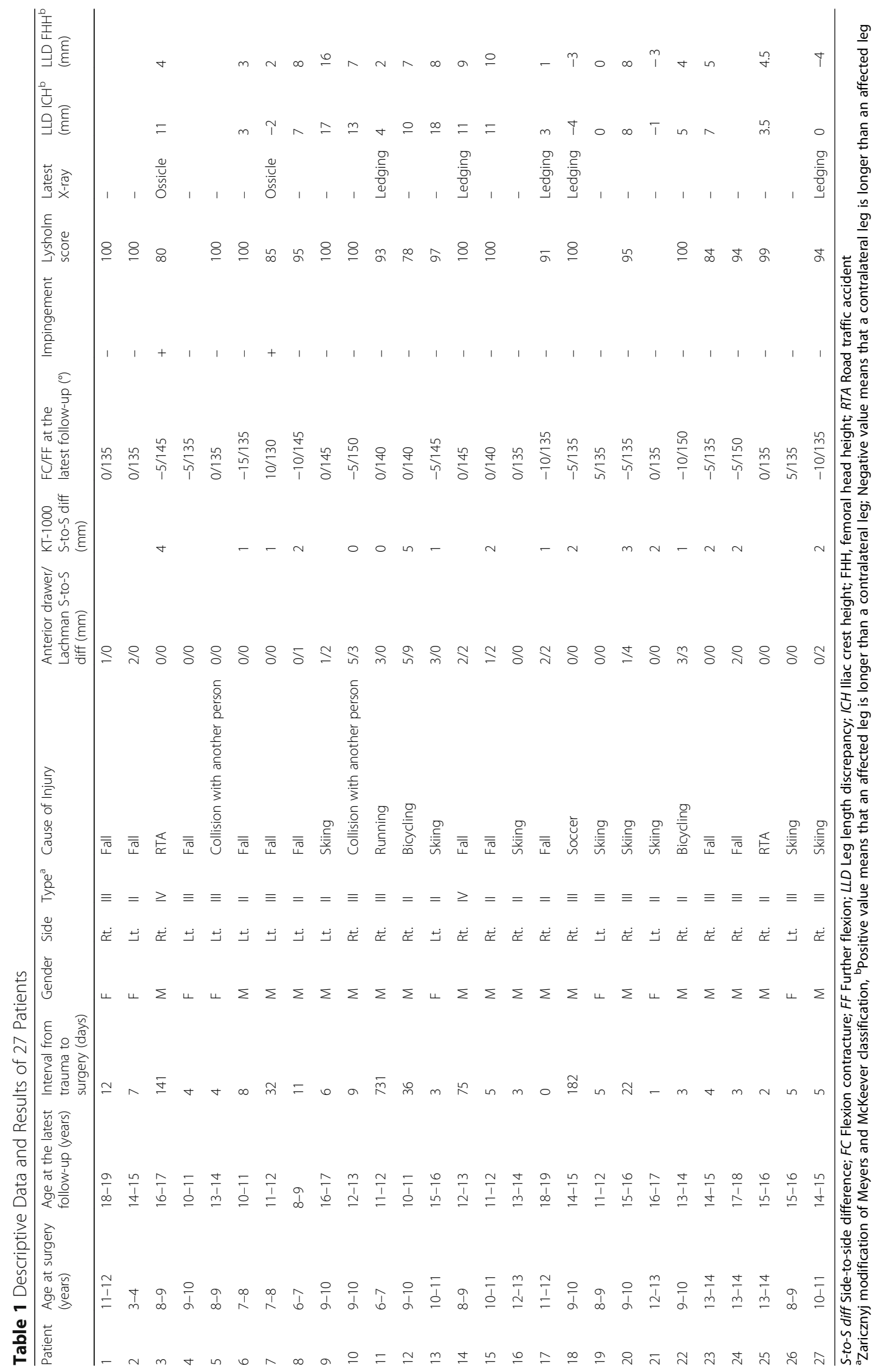




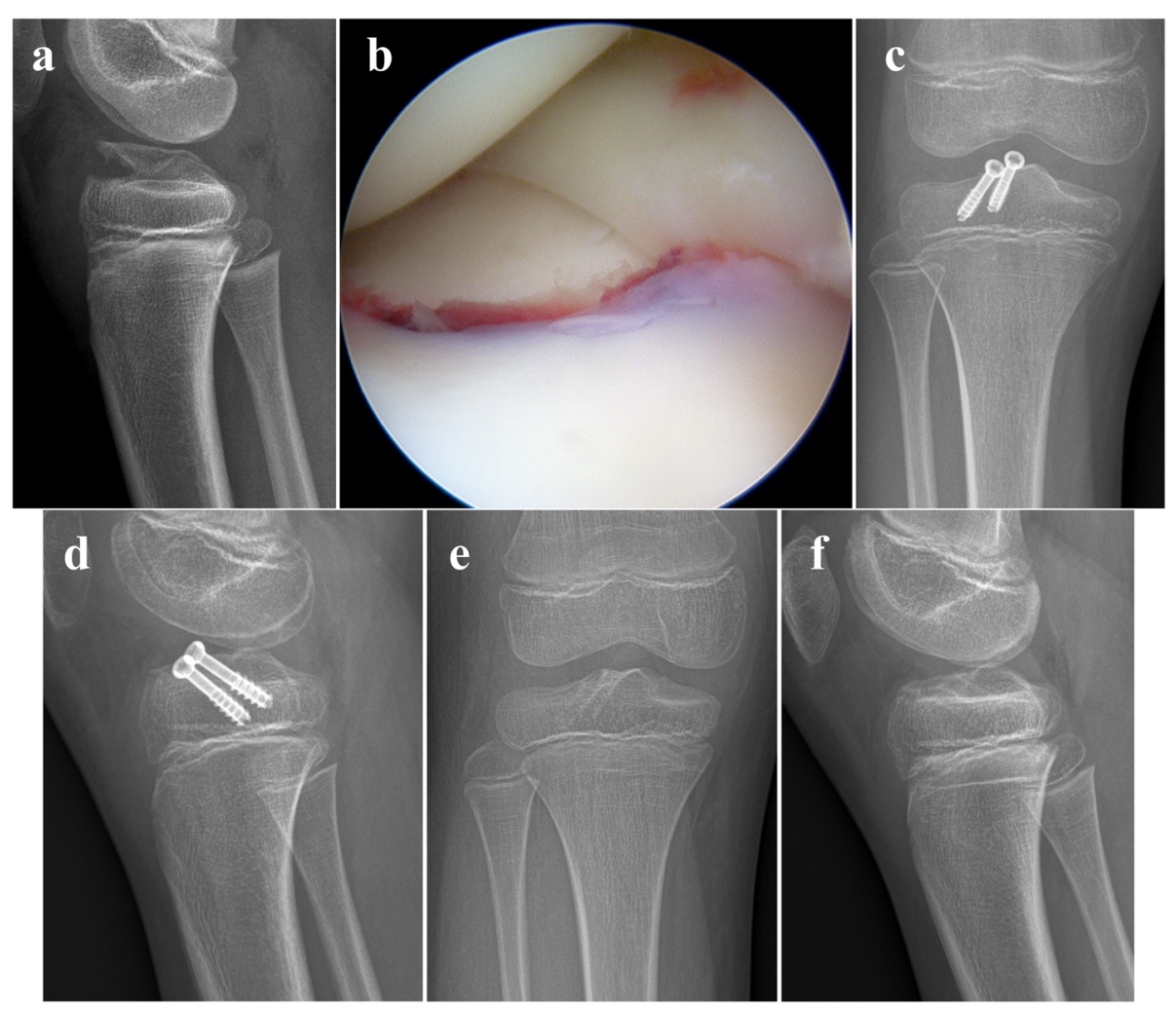

Fig. 1 a A radiograph of a 10-11 year-old girl with tibial eminence fracture. $\mathbf{b}$ Anterior horn of medial meniscus entrapped under the avulsed fragment. c, d Radiographs taken at postoperative one month. The avulsed fragment was fixed with two $5.0 \mathrm{~mm}$ cannulated screws. e, $\mathbf{f}$ Radiographs taken at postoperative one year. Screws were removed. Her Lysholm knee screw was 100 . She did not have instability of the knee

tension of the ligament was acceptable. He complained intermittent pain and swelling of the knee after sports activity, although he had no pain during daily life activities.

The mean Lysholm knee score was $94.8 \pm 6.8$ (range, 78 to $100)$ at the latest follow-up. The score was more than 90 in $18(82 \%)$ patients, 80 to 90 in $3(14 \%)$ patients, and 78 in 1 (5\%) patient who showed instability of the knee in physical examination and KT-1000 arthrometer measurement. The mean Lysholm score was $96.8 \pm 4.5$ (range, 84 to 100) in 16 patients whose interval from trauma to surgery was less than 30 days, and $89.3 \pm 9.8$ (range, 78 to 100) in 6 patients whose interval from trauma to surgery was more than 30 days $(p=$ $0.134)$. The correlation between the degree of laxity measured by KT-1000 or Lachman test and the Lysholm scores was not statistically significant ( $p=0.088$ and $p=0.910$, respectively).

\section{Radiological outcomes}

There was no case showing violation of proximal tibial physis by screws on postoperative radiographs. In 7 (26\%) patients, radiologic abnormalities were found at the latest follow-up. Five (19\%) had ledging which was prominent tibial eminence (Fig. 3). This might be caused by malunion and overgrowth of the avulsed fragment. Two (7\%) were small ossicles above the tibial plateau (Fig. 3). Four of these 7 patients underwent operation at more than 30 days after the trauma. Extension deficit was not observed in these patients except one who underwent revision surgery due to re-displacement of avulsed fragment.

The length of the affected lower limb was $6.2 \pm 5.9 \mathrm{~mm}$ longer (range, -4.0 to $18.3 \mathrm{~mm}$ ) than that of the contralateral lower limb measured against iliac crest height. It was $4.4 \pm$ $4.7 \mathrm{~mm}$ longer (range, -3.0 to $16.4 \mathrm{~mm}$ ) measured against femoral head height. In 10 (50\%) patients, the affected leg was more than $5 \mathrm{~mm}$ longer than the contralateral leg measured against iliac crest height. In another 10 (50\%) patients, the difference in length between both legs was less than $5 \mathrm{~mm}$. No patient whose contralateral leg was more than $5 \mathrm{~mm}$ longer than the affected leg. The mean length of femora of the affected side was $3.6 \pm 4.1 \mathrm{~mm}$ longer (range, -3.0 to $10.8 \mathrm{~mm}$ ) than that of the contralateral side. The mean length of tibiae of affected side was $2.3 \pm 3.4 \mathrm{~mm}$ longer (range, -6.0 to $9.3 \mathrm{~mm}$ ) than that of the contralateral side.

Associated knee injuries based on preoperative MRI and arthroscopic findings are summarized in Table 2 . Six patients had lateral meniscal tear which was treated with partial meniscectomy (4 patients) or meniscal repair (2 patients). One medial meniscal tear was treated with partial meniscectomy. 


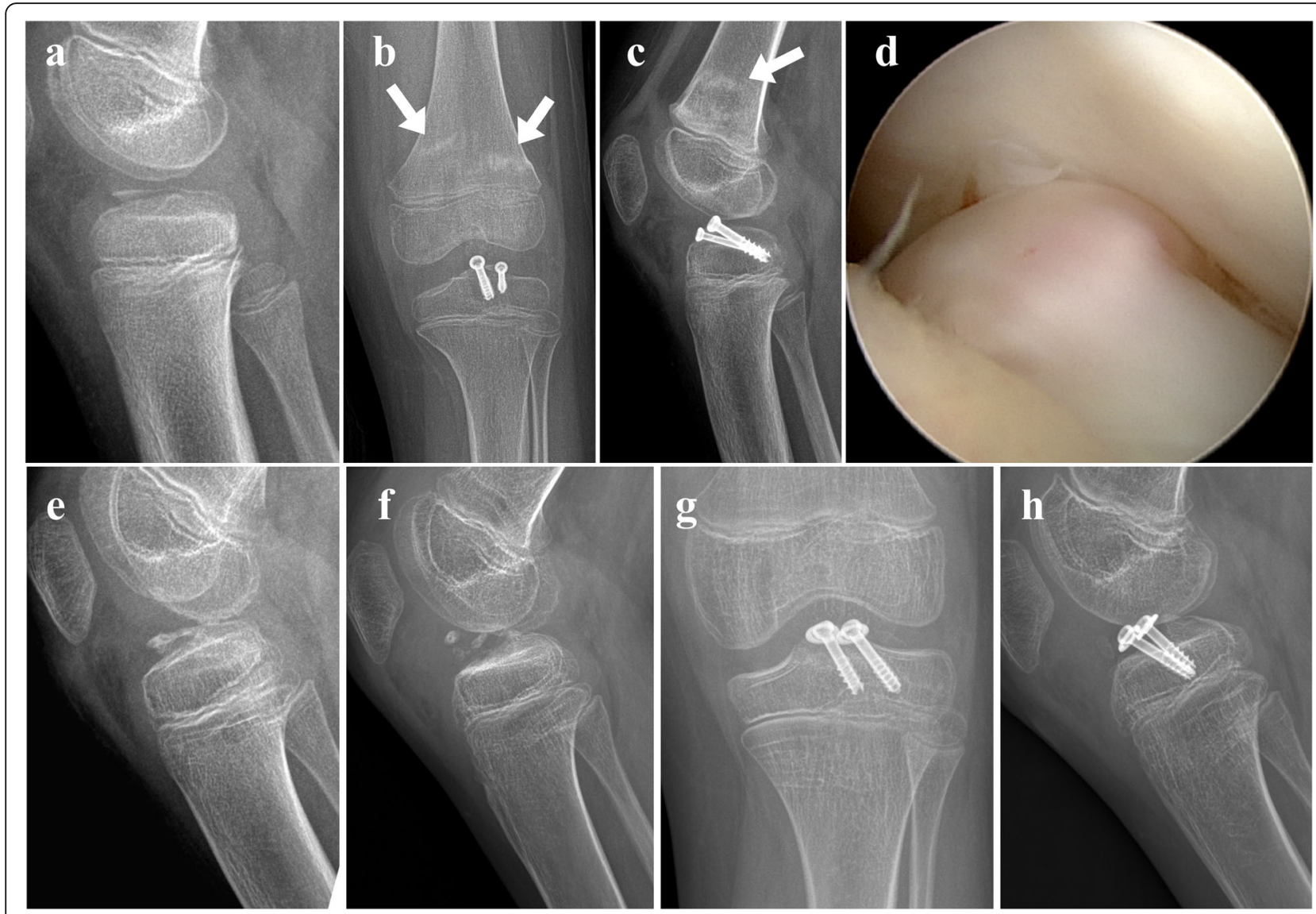

Fig. 2 a A 8-9 year-old boy visited the clinic at 32 days post trauma with type III tibial eminence fracture. b, c Radiographs taken at postoperative 2.5 months. Incomplete distal femoral metaphyseal fracture (arrow) occurred during vigorous physical therapy. $\mathbf{d}$ While removing screws, it was found that the head of $5.0 \mathrm{~mm}$ screw impinged against the lateral portion of the medial femoral condyle and caused extension deficit of the knee. e Radiolucent gap between avulsed fragment and host bone was found on the day of screw removal. $\mathbf{f}$ A radiograph taken at postoperative 18 months. He was lost to follow-up for 1 year. He returned to the clinic with flexion contracture of $25^{\circ}$ and re-displaced avulsed fragment. $\mathbf{g}, \mathbf{h}$ He underwent open reduction and internal fixation with two $5.0 \mathrm{~mm}$ screws in conjunction with two washers for re-displaced fragments

\section{Discussion}

The results show that arthroscopically assisted cannulated screw fixation is an effective and safe method for tibial eminence fracture in pediatric patients. Previous studies have described that fixation with a relatively large screw, compared to the small avulsed fragment, is technically demanding and can cause comminution of the bony fragment [28, 37, 38]. However, this complication was not found in this study. Union was achieved in almost all patients using a washer combined with a screw depending on the size of avulsed fragment and fracture pattern, consistent with prior results [32]. Other authors expressed concern that synovial leakage might occur after using a larger portal for a washer [27]. However, this complication did not occur in our series. To prevent posterior displacement of the avulsed fragment during screw insertion and consequent increased laxity, operators need to pay attention to the sagittal angle of the screw. Inserting two guide pins before screw insertion may help to prevent displacement and rotation of the fragment.
Arthrofibrosis developed in only one patient. This frequency is much less than the result of a previous multicenter study reporting an arthrofibrosis frequency of $10 \%$ in 205 patients treated with various surgical methods [14]. The authors immobilized the knee in full extension for 4 to 6 weeks in the majority of patients, which was longer than the 3 to 4 weeks in the present study. A previous systematic review reported that no patient developed arthrofibrosis in the screw fixation group compared to $6.3 \%$ of patients treated by suture fixation [39]. The data indicate that early range of motion exercise following firm fixation with cannulated screws might reduce the occurrence of arthrofibrosis.

A previous systematic review reported that $82 \%$ patients had laxity on both anterior drawer and Lachman test, while another systematic review reported abnormality on anterior drawer or Lachman test in $20 \%$ of patients $[39,40]$. These rates are higher than presently observed. The discrepancy in instability might be attributable to a real difference of laxity or by heterogeneous criteria used to evaluate instability. In 


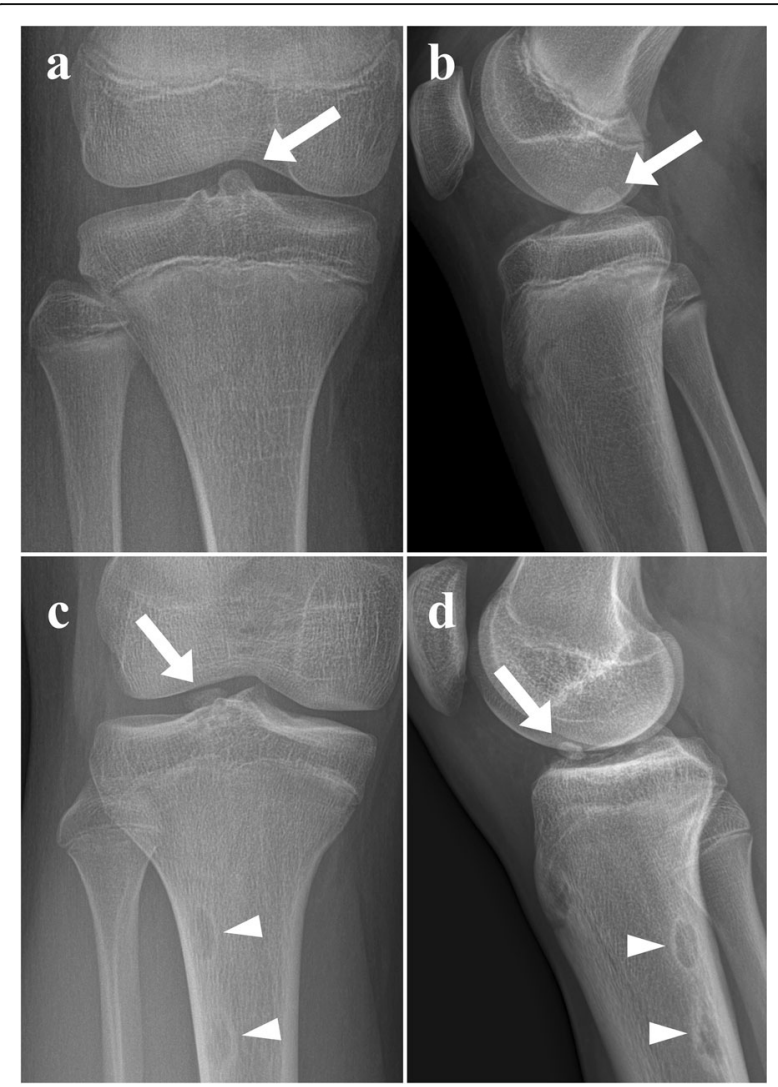

Fig. 3 a, b Radiographs showing ledging (arrow), a prominent tibial eminence, possibly caused by malunion and overgrowth of the avulsed fragment. c, $\mathbf{d}$ In two patients, ossicles (arrow) were found above the tibial plateau. One patient had well demarcated intracortical osteolytic lesions (arrowhead) in the posterolateral aspect of proximal tibia

this study, side-to-side differences on physical examinations and KT-1000 arthrometer measurement were used to determine instability for pediatric patients, who are generally suppler than adults. However, another study used the absolute value on Lachman test to judge instability [33]. Similar to the results of other studies, there was no significant relationship between laxity and subjective symptom in the current study [33, 41]. However, a patient who had 5 to $10 \mathrm{~mm}$ of side-to-side difference on physical examinations and KT-1000 arthrometer also had pain and

Table 2 Details of the associated knee injury

\begin{tabular}{ll}
\hline$N=26$ & No. \\
\hline None & $14(54 \%)$ \\
Bone contusion in the femoral lateral condyle & $5(19 \%)$ \\
Lateral meniscal tear & $4(15 \%)$ \\
Lateral meniscal tear and bone contusion & $1(4 \%)$ \\
in the femoral lateral condyle & $1(4 \%)$ \\
Lateral and medial meniscal tear & $1(4 \%)$ \\
Segond fracture &
\end{tabular}

swelling of the knee after strenuous exercise and recorded the lowest Lysholm score.

High Lysholm knee scores have been reported, regardless of surgical methods or fixation devices [27, 39, 42, 43]. The scores were also high in our study. Since these uniform high scores might be due to a ceiling effect of Lysholm knee score [44], caution is needed when interpreting Lysholm score as a surgical outcome. In the current study, Lysholm scores of patients who underwent surgery more than 30 days after trauma were less than those of patients who underwent surgery within 30 days after trauma. However, their differences were not statistically significant. This might be due to type-II error.

Impingement of screw head on femoral condyle or trochlea has been rarely reported. A previous study of epiphyseal or transphyseal cannulated screw fixation related no case of chondral damage from a protruded screw [45]. Another case report introduced a patient who had $15^{\circ}$ of extension deficit and chondral damage after an epiphyseal screw fixation with a toothed washer for type II fracture [46]. The authors assumed that use of a washer might have induced bulging of the screw head, resulting in extension impingement. However, a washer was not used in the two patients who had impingement in the present study. They underwent surgery at more than 30 days after trauma and two $5.0 \mathrm{~mm}$ screws were used. When the period between trauma and surgery is long or diameter of a screw is large, careful inspection for impingement should be made for the whole range of motion. Intercondylar notchplasty may be considered.

Nonunion rarely occurs after a tibial eminence fracture $[39,47]$. Presently, only one patient underwent additional surgery due to nonunion. On the latest radiographs, 5 (19\%) patients had prominent tibial eminence, consistent with results of a previous study showing $15 \%$ patients with ledging [27]. In the latter series, one of four ledgings caused an impingement phenomenon. In the current study, however, patients with ledging did not show extension deficit except one who received revision surgery.

Some previous studies have reported physeal growth disturbance after treatment for tibial eminence fracture [32$34,39,47,48]$. However, LLD was rarely evaluated. Ahn and colleagues described that 2 of 5 children have LLD of $1 \mathrm{~cm}$ (the affected legs is longer) after arthroscopic reduction and suture fixation [48]. In our study, the mean length of the affected leg was longer than that of the contralateral leg. Interestingly, both tibiae and femora of the affected side were longer than those of the contralateral side. Because LLD was not measured preoperatively, we cannot conclusively say that tibial eminence fracture is prone to occur in a longer leg or can make the affected leg longer.

Entrapment of the meniscus or intermeniscal ligament between the avulsed fragment and host bone can obstruct the reduction of a fracture $[49,50]$. A study from the United States reported this finding after tibial eminence fracture in 
over 50\% of patients [49]. Another Western study described that $59 \%$ patients have interposition of intermeniscal ligament under the avulsed fragment [30]. In our study of Korean patients, only $19 \%$ of the patients had these findings, although distribution of fracture type was similar to that in previous studies. In contrast, associated injuries including meniscal tear were more common in our study than those in Western studies [27, 33, 49]. A Japanese study also reported associated meniscal tear in 30\% of patients [51], similar to our result. More data are needed to confirm this difference between Asian and Western patients.

This study had several limitations. First, because the study design was a retrospective case series, there was no control group treated with other methods. Second, results of some examinations, such as KT-1000 arthrometer and whole leg radiograph, in some patients could not be obtained due to their circumstances. This might have caused selection bias. Third, because the number of patients with type IV fracture was small, it was difficult to assess the outcome of cannulated screw fixation for type IV fracture. Fourth, Lachman and anterior drawer tests were performed manually without taking special landmarks, which may lead to low accuracy and reliability of these tests. And the result of pivot shift test which is also commonly performed in the patients with ACL insufficiency was not presented. Fifth, although we showed Lysholm score as a functional outcome scale, it would be better if we obtained Tegner or Marx activity scale together. Lastly, the sample size was not large, in some analyses, to verify the statistical significance.

\section{Conclusions}

Arthroscopically assisted cannulated screw fixation for tibial eminence fracture in children and adolescents shows satisfactory clinical and radiological outcomes. Union can be achieved in almost every patient, and postoperative function of the knee is excellent. The occurrences of arthrofibrosis, instability, and screw head impingement are low, and the risk of violation of proximal tibial physis by screws are minimal.

\section{Abbreviations}

ACL: Anterior cruciate ligament; AP: Anteroposterior; FC: Flexion contracture; FF: Further flexion; FHH: Femoral head height; ICH: Iliac crest height; LLD: Leg length discrepancy; S-to-S diff: Sde-to-side difference; RTA: road traffic accident

\section{Acknowledgements}

Not applicable.

\section{Funding}

No funding was obtained for this study.

\section{Availability of data and materials}

The datasets used and analyzed during the current study are available from the corresponding author on reasonable request.

\section{Authors' contributions}

CHS and DJL drafted the manuscript and performed data collection and data analysis. IHC, TJC, and WJY conceived of the study, participated in the design of the study, performed data interpretation, and participated in coordination. All authors read and approved the final manuscript.

\section{Ethics approval and consent to participate}

This study was approved by Seoul National University College of Medicine/ Seoul National University Hospital Institutional Review Board. Informed consent was waived because this study was a retrospective chart and radiograph review study and research activities did not involve any additional risk for patients.

Consent for publication

Not applicable.

\section{Competing interests}

The authors declare that they have no competing interests.

\section{Publisher's Note}

Springer Nature remains neutral with regard to jurisdictional claims in published maps and institutional affiliations.

Received: 21 July 2017 Accepted: 31 January 2018

Published online: 06 February 2018

\section{References}

1. Molander ML, Wallin G, Wikstad I. Fracture of the intercondylar eminence of the tibia: a review of 35 patients. J Bone Joint Surg Br. 1981;63-B(1):89-91.

2. Meyers $M H, M$. MF. Fracture of the intercondylar eminence of the tibia. J Bone Joint Surg Am. 1959;41-A(2):209-20. discussion 20-2

3. Skak SV, Jensen TT, Poulsen TD, Sturup J. Epidemiology of knee injuries in children. Acta Orthop Scand. 1987;58(1):78-81.

4. Zaricznyj B. Avulsion fracture of the tibial eminence: treatment by open reduction and pinning. J Bone Joint Surg Am. 1977;59(8):1111-4.

5. Lafrance RM, Giordano B, Goldblatt J, Voloshin I, Maloney M. Pediatric tibial eminence fractures: evaluation and management. J Am Acad Orthop Surg. 2010;18(7):395-405.

6. Meyers $\mathrm{MH}, \mathrm{McK}$ eever FM. Fracture of the intercondylar eminence of the tibia. J Bone Joint Surg Am. 1970;52(8):1677-84.

7. Berg EE. Pediatric tibial eminence fractures: arthroscopic cannulated screw fixation. Arthroscopy. 1995;11(3):328-31.

8. Keshet D, Zaidman M, Eidelman M. Treatment of avulsion fractures of the intercondylar eminence by medial parapatellar approach, open reduction and cross wire fixation. J Pediatr Orthop B. 2015;24(4):321-5.

9. Johnson DL, Durbin TC. Physeal-sparing tibial eminence fracture fixation with a headless compression screw. Orthopedics. 2012;35(7):604-8.

10. Sawyer GA, Hulstyn MJ, Anderson BC, Schiller J. Arthroscopic suture bridge fixation of tibial intercondylar eminence fractures. Arthrosc Tech. 2013;2(4): e315-8.

11. Su WR, Wang PH, Wang HN, Lin CJ. A simple, modified arthroscopic suture fixation of avulsion fracture of the tibial intercondylar eminence in children. J Pediatr Orthop B. 2011:20(1):17-21.

12. Brunner S, Vavken P, Kilger R, Vavken J, Rutz E, Brunner R, Camathias C. Absorbable and non-absorbable suture fixation results in similar outcomes for tibial eminence fractures in children and adolescents. Knee Surg Sports Traumatol Arthrosc. 2016;24(3):723-9.

13. Nwachukwu BU, McFeely ED, Nasreddine A, Udall JH, Finlayson C, Shearer DW, Micheli LJ, Kocher MS. Arthrofibrosis after anterior cruciate ligament reconstruction in children and adolescents. J Pediatr Orthop. 2011;31(8): 811-7.

14. Vander Have KL, Ganley TJ, Kocher MS, Price CT, Herrera-Soto JA. Arthrofibrosis after surgical fixation of tibial eminence fractures in children and adolescents. Am J Sports Med. 2010;38(2):298-301.

15. Gholve PA, Voellmicke KV, Guven M, Potter HG, Rodeo SA, Widmann RF. Arthrofibrosis of the knee after tibial spine fracture in children: a report of two complicated cases. HSS J. 2008;4(1):14-9.

16. Petsche TS, Hutchinson MR. Loss of extension after reconstruction of the anterior cruciate ligament. J Am Acad Orthop Surg. 1999;7(2):119-27.

17. Larsen MW, Garrett WE, Jr., Delee JC, Moorman CT, 3rd. Surgical management of anterior cruciate ligament injuries in patients with open physes. J Am Acad Orthop Surg 2006;14(13):736-744.

18. Yoo WJ, Kocher MS, Micheli $\amalg$. Growth plate disturbance after transphyseal reconstruction of the anterior cruciate ligament in skeletally immature adolescent patients: an MR imaging study. J Pediatr Orthop. 2011;31(6):691-6.

19. Sawyer GA, Anderson BC, Paller D, Schiller J, Eberson CP, Hulstyn M. Biomechanical analysis of suture bridge fixation for tibial eminence fractures. Arthroscopy. 2012;28(10):1533-9. 
20. Mahar AT, Duncan D, Oka R, Lowry A, Gillingham B, Chambers H. Biomechanical comparison of four different fixation techniques for pediatric tibial eminence avulsion fractures. J Pediatr Orthop. 2008;28(2):159-62.

21. In Y, Kwak DS, Moon CW, Han SH, Choi NY. Biomechanical comparison of three techniques for fixation of tibial avulsion fractures of the anterior cruciate ligament. Knee Surg Sports Traumatol Arthrosc. 2012;20(8):1470-8.

22. Hapa O, Barber FA, Suner G, Ozden R, Davul S, Bozdag E, Sunbuloglu E. Biomechanical comparison of tibial eminence fracture fixation with highstrength suture, EndoButton, and suture anchor. Arthroscopy. 2012;28(5):681-7.

23. Anderson CN, Nyman JS, McCullough KA, Song Y, Uppuganti S, O'Neill KR, Anderson AF, Dunn WR. Biomechanical evaluation of physeal-sparing fixation methods in tibial eminence fractures. Am J Sports Med. 2013;41(7):1586-94.

24. Senekovic $V$, Balazic M. Bioabsorbable sutures versus screw fixation of displaced tibial eminence fractures: a biomechanical study. Eur J Orthop Surg Traumatol. 2014;24(2):209-16.

25. Ahn JH, Lee YS, Lee DH, Ha HC. Arthroscopic physeal sparing all inside repair of the tibial avulsion fracture in the anterior cruciate ligament: technical note. Arch Orthop Trauma Surg. 2008;128(11):1309-12.

26. Huang TW, Hsu KY, Cheng CY, Chen LH, Wang CJ, Chan YS, Chen WJ. Arthroscopic suture fixation of tibial eminence avulsion fractures. Arthroscopy. 2008:24(11):1232-8.

27. Reynders P, Reynders K, Broos P. Pediatric and adolescent tibial eminence fractures: arthroscopic cannulated screw fixation. J Trauma. 2002;53(1):49-54.

28. Wouters DB, de Graaf JS, Hemmer PH, Burgerhof JG, Kramer WL. The arthroscopic treatment of displaced tibial spine fractures in children and adolescents using meniscus arrows(R). Knee Surg Sports Traumatol Arthrosc. 2011;19(5):736-9.

29. Furlan D, Pogorelic Z, Biocic M, Juric I, Mestrovic J. Pediatric tibial eminence fractures: arthroscopic treatment using K-wire. Scand J Surg. 2010;99(1):38-44.

30. Hunter RE, Willis JA. Arthroscopic fixation of avulsion fractures of the tibial eminence: technique and outcome. Arthroscopy. 2004;20(2):113-21.

31. Pan RY, Yang JJ, Chang JH, Shen HC, Lin LC, Lian YT. Clinical outcome of arthroscopic fixation of anterior tibial eminence avulsion fractures in skeletally mature patients: a comparison of suture and screw fixation technique. J Trauma Acute Care Surg. 2012;72(2):E88-93.

32. Senekovic $V$, Veselko M. Anterograde arthroscopic fixation of avulsion fractures of the tibial eminence with a cannulated screw. five-year results Arthroscopy. 2003;19(1):54-61.

33. Kocher MS, Foreman ES, Micheli LJ. Laxity and functional outcome after arthroscopic reduction and internal fixation of displaced tibial spine fractures in children. Arthroscopy. 2003;19(10):1085-90.

34. Najdi H, Thevenin-Lemoine C, Sales de Gauzy J, Accadbled F. Arthroscopic treatment of intercondylar eminence fractures with intraepiphyseal screws in children and adolescents. Orthop Traumatol Surg Res. 2016;102(4):447-51.

35. Lysholm J, Gillquist J. Evaluation of knee ligament surgery results with special emphasis on use of a scoring scale. Am J Sports Med. 1982;10(3):150-4.

36. Meyers MHMF. Fractures of the intercondylar eminence of the tibia. J Bone Joint Surg Am. 1959;41:209-22.

37. EE B. Pediatric Tibia1 eminence fractures: arthroscopic cannulated screw fixation. Arthroscopy. 1995;11(3):328-31.

38. Tudisco C, Giovarruscio R, Febo A, Savarese E, Bisicchia S. Intercondylar eminence avulsion fracture in children: long-term follow-up of 14 cases at the end of skeletal growth. J Pediatr Orthop B. 2010;19(5):403-8.

39. Gans I, Baldwin KD, Ganley TJ. Treatment and management outcomes of Tibial eminence fractures in pediatric patients: a systematic review. Am J Sports Med. 2014:42(7):1743-50.

40. Bogunovic L, Tarabichi M, Harris D, Wright R. Treatment of tibial eminence fractures: a systematic review. J Knee Surg. 2015;28(3):255-62.

41. Baxter MP, Fractures WJJ. Of the tibial spine in children. An evaluation of knee stability. J Bone Joint Surg Br. 1988;70(2):228-30.

42. Janarv PM, Westblad P, Johansson C, Hirsch G. Long-term follow-up of anterior tibial spine fractures in children. J Pediatr Orthop. 1995;15(1): 63-8.

43. Perugia D, Basiglini L, Vadala A, Ferretti A. Clinical and radiological results of arthroscopically treated tibial spine fractures in childhood. Int Orthop. 2009;33(1):243-8.

44. Ra HJ, Kim HS, Choi JY, Ha JK, Kim JY, Kim JG. Comparison of the ceiling effect in the Lysholm score and the IKDC subjective score for assessing functional outcome after ACL reconstruction. Knee. 2014;21(5):906-10.

45. Parikh SN, Myer D, Eismann EA. Prevention of Arthrofibrosis after arthroscopic screw fixation of Tibial spine fracture in children and adolescents. Orthopedics. 2014;37(1):e58-e65.
46. Tsai T-Y, Chan J-H, Yeh Y-K, Chuang F-K, Liu C-W, Wang S-J. Malpractice of epiphyseal cannulated screw fixation in a child with avulsion fracture of the tibial eminence complicating with lack of knee extension and distal femoral fracture. J Med Sci. 2009;29(5):289-92.

47. Coyle C, Jagernauth S, Ramachandran M. Tibial eminence fractures in the paediatric population: a systematic review. J Child Orthop. 2014;8(2):149-59.

48. Ahn JH, Yoo JC. Clinical outcome of arthroscopic reduction and suture for displaced acute and chronic tibial spine fractures. Knee Surg Sports Traumatol Arthrosc. 2005;13(2):116-21.

49. Kocher MS, Micheli $\sqcup$, Gerbino P, Hresko MT. Tibial eminence fractures in children: prevalence of meniscal entrapment. Am J Sports Med. 2003;31(3):404-7.

50. Burstein DB, Viola A, Fulkerson JP. Entrapment of the medial meniscus in a fracture of the tibial eminence. Arthroscopy. 1988;4(1):47-50.

51. Park HJ, Urabe K, Naruse K, Aikawa J, Fujita M, Itoman M. Arthroscopic evaluation after surgical repair of intercondylar eminence fractures. Arch Orthop Trauma Surg. 2007;127(9):753-7.

\section{Submit your next manuscript to BioMed Central and we will help you at every step:}

- We accept pre-submission inquiries

- Our selector tool helps you to find the most relevant journal

- We provide round the clock customer support

- Convenient online submission

- Thorough peer review

- Inclusion in PubMed and all major indexing services

- Maximum visibility for your research

Submit your manuscript at www.biomedcentral.com/submit
) Biomed Central 